\title{
LÓPEZ ULLA, Juan Manuel (dir.) y SÁEZ GONZÁLEZ, Jesús (coord.), Combatiendo la violencia contra la mujer: experiencias europeas y americanas, Aranzadi, Cizur Menor (Navarra), $1^{\mathrm{a}}$ ed., 2020, 600 páginas
}

\author{
ROCÍO GUADALUPE QUIÑNES ANDRADE* \\ Profesora de Derechos Humanos y Derecho Internacional \\ Universidad Iberoamericana (México) \\ roguquian@gmail.com
}

Este libro, dirigido por Juan Manuel López Ulla y coordinado por Jesús Sáez González, ambos profesores de la Universidad de Cádiz, es la tercera obra colectiva que ha sido publicada en el marco de la Red Iberoamericana de Estudios Jurídicos 1812, de la que forman parte 18 instituciones universitarias coordinadas por la Universidad de Cádiz. (Las obras anteriores fueron: Derechos Humanos y orden constitucional en Iberoamérica, Civitas, 2011, y La justicia constitucional en Iberoamérica, Universidad de Cádiz, 2011).

En esta obra, han participado quince investigadoras e investigadores de diversas universidades iberoamericanas, de los cuales, cinco pertenecen a la Facultad de Derecho de esta Universidad. Además se cuenta con la participación de académicos de la Universidad de Sevilla, la Universidad Nacional Autónoma de México, Universidad Michoacana de San Nicolás de Hidalgo (México), Universidad Centroamericana (Nicaragua), Universidad de Mendoza (Argentina), Universidad Lusíada (Portugal), Universidad de Bolonia (Italia), y del Superior Tribunal Militar de Brasil.

Debido a la procedencia de los autores, sus centros de adscripción y sus diversos campos de estudio, esta obra presenta un análisis multidisciplinario comparado, tanto jurídico como social de la violencia contra la mujer, que va desde la tutela nacional e internacional de los tribunales

Cómo citar este trabajo: QUIÑONES ANDRADE, Rocío Guadalupe, "LÓPEZ ULLA, Juan Manuel (dir.) y SÁEZ GONZÁLEZ, Jesús (coord.), Combatiendo la violencia contra la mujer: experiencias europeas y americanas, Aranzadi, Cizur Menor (Navarra), $1^{\mathrm{a}}$ ed., 2020, 600 páginas", Revista de Estudios Jurídicos y Criminológicos, ISSN-e: 2660-7964, n. ${ }^{\circ}$ 2, Universidad de Cádiz, 2020, pp. 257-260, DOI: https://doi.org/10.25267/REJUCRIM.2020.i2.12

${ }^{*}$ Candidata a doctora por el Instituto de Investigaciones Jurídicas de la Universidad Nacional Autónoma de México (México) y la Universidad de Cádiz (España). 
en la materia, hasta el reflejo de la sociedad machista y misógina en la literatura y las redes sociales.

$Y$ es que el tema, merece un estudio de tal envergadura. La violencia contra las mujeres es la consecuencia más general de la discriminación de género, y, como se expresa en la obra tratada, es una problemática mayúscula que se debe combatir desde todos los ámbitos sociales, y en todos los niveles de la impartición de justicia. Ésta se instala en una sociedad machista, y es fomentada por la falta de prevención, el menosprecio de las autoridades ante las denuncias y los obstáculos administrativos en las investigaciones, que generan impunidad.

Por ello, cada uno de los autores de esta obra colectiva, analiza la violencia contra la mujer partiendo de una causa específica, ya sea que esta derive de un problema sistémico en la impartición de justicia del Estado o de una cultura machista que genera el menosprecio y la anulación de las mujeres.

De esta manera, el libro comienza con la participación de Juan Manuel López Ulla, en el capítulo I, quien plantea el tema de las desapariciones forzadas en dos rubros generales: cuando las mujeres son víctimas de este delito de lesa humanidad, y cuando alguno de sus familiares es desparecido por una autoridad. En el primer caso, aborda tanto el problema de impunidad que se tiene en diversos países de Iberoamérica, como la discriminación que sufren las mujeres por razón de género en los procesos de investigación. En el segundo caso expone que la mujer debe ser considerada víctima directa y por ello, es necesaria la protección de sus derechos al realizar las investigaciones conducentes que lleven al conocimiento de la verdad.

En el capítulo II, María Paula Quiroga Corti, realiza una interesante aportación, sobre el combate de la violencia contra las mujeres desde la Corte Suprema de Justicia de Argentina. Estudia el fallo "Gongora", en el que el máximo órgano judicial argentino interpreta la Convención de Belém do Pará, determinando que todos los casos de violencia de género deben ser conocidos en la jurisdicción penal, lo que ha causado controversia en dicho país.

En el capítulo III, Jesús Sáez González nos habla de las marcadas diferencias que existen entre la violencia de género y violencia entre las mujeres. Establecido el contexto del estudio violencia contra las mujeres- brinda un panorama sobre la valoración policial del riesgo, una vez que una mujer realiza una denuncia por violencia en España, con el fin de tomar las medidas adecuadas para impedir nuevas conductas de violencia. Concluye su estudio, señalando que la determinación de las medidas de protección de las mujeres violentadas en España, son particularmente difíciles en el caso de migrantes.

El capítulo IV, escrito por María Ángeles Pérez Marín, se trata la compleja protección de los derechos de las víctimas de violencia de genero en el sistema de la Unión Europea y la necesidad imperiosa de garantizar sus derechos a la vida, seguridad, libre circulación y residencia dentro del territorio de la Unión. Hace una especial referencia a la transportación de las directivas de la Unión en territorio español. 
Jorge A. Coussirat, presenta en el capítulo V, un análisis sobre la normativa y el proceso penal que se lleva a cabo en Argentina, en los casos de violencia de género. Habla sobre la evolución que se ha tenido en Argentina en estos casos y como se ha adaptado su legislación a los tratados interamericanos que el Estado ha signado sobre la protección de los derechos de la mujer.

La suscrita, he colaborado en esta obra colectiva, redactando el capítulo VI, en donde se expone la forma en la que el Estado mexicano ha dado cumplimiento en los últimos años a las cuatro sentencias interamericanas que han sido dictadas en su contra, en donde se le ha declarado responsable de violencia contra las mujeres por diversos motivos, especialmente, por feminicidios, violaciones y tortura sexual. En este capítulo se ha hecho especial referencia en la falta del impacto social que han tenido las sentencias a pesar del cumplimiento estatal.

El capítulo VII presenta el trabajo de Nicolás Egües, que expone la lucha de las mujeres, específicamente del movimiento feminista argentino que ha logrado generar grandes cambios en las políticas públicas del país para combatir la violencia contra las mujeres y que ha llegado a impactar su Constitución.

Por su parte, Annalisa Verza estudia en el capítulo VIII, las nuevas formas de violencia contra la mujer, generadas en el espacio cibernético, como la masculinidad tóxica en las redes sociales, el cyberstalking, revenge porn, la sextorsión, y los discursos del odio en internet, que son fomentadas por el anonimato que brinda el ciberespacio.

Por su parte, María Elizabeth Guimarães Teixeira Rocha, realiza una crítica en el capítulo IX a la misoginia y el machismo que existe al interior de las fuerzas armadas en Brasil. Aborda esta problemática al afirmar que colisiona con la protección de los derechos de las mujeres que forman parte de esta institución que, al ser una minoría, es rechazada y discriminada.

En el capítulo X de la obra, Rodrigo Pardo Fernández realiza un estudio sobre las obras literarias en donde se plasma la agresión, cosificación y nulificación de la figura de la mujer, y analiza si éstas son capaces de establecer visiones críticas del entorno extratextual, con el fin de que su lectura contribuya a la reflexión sobre problemas sociales, y así poder visibilizar una problemática de la cual, lamentablemente no se tiene nociones de su gravedad por la sociedad, y propone que se esta manera se podría encontrar alguna solución.

Suhey Mercedes Fúnez Narváez analiza en el capítulo XI de la obra, si existe un derecho penal diferenciado cuando se juzga la violencia contra las mujeres en Nicaragua. En su aportación, la autora estudia las diferencias que existen entre el juzgamiento de los delitos generales y aquellos cometidos en contra de mujeres y destaca la necesidad de que se juzgue bajo una tutela especial la violencia contra la mujer, con el fin de que exista una igualdad entre las partes en una sociedad machista.

En el capítulo XII, Ana Sofia Gomes, estudia el sistema de impartición de justicia en Portugal, especialmente en el caso del juzgamiento de la violencia contra las mujeres, y determina que la legislación portuguesa es adecuada, pero las autoridades aplican deficientemente la evaluación 
del riesgo, lo que deriva en la falta de aplicación de medidas preventivas adecuadas que mantienen en riesgo a las mujeres violentadas.

Diego J. Bernal Caputto expone en el capítulo XIII, la importancia del papel del letrado en los juicios sobre violencia de género con el fin de garantizar, los derechos del acusado y especialmente, los de la víctima.

El capítulo XIV, redactado por Ana María Barba Fernández, analiza la violencia de género en las relaciones de pareja adolecentes en España. Aborda diferentes tópicos, como el stalking, sexting y sextorsion, que son lamentablemente comunes en la actualidad, y en donde la mayoría de las víctimas son menores de edad, que aún no cuentan con la suficiente visibilidad.

Por último, en el capítulo XV, Ana Ríos Cabrera realiza una crítica del artículo 416.1 de la Ley de Enjuiciamiento Criminal española en relación con la dispensa de la obligación de declarar en los casos de víctimas de violencia de género, destacando que se debe hacer una revisión profunda del mismo, ya que no satisface de modo alguno la protección contra la violencia de género.

Sin duda, cada uno de los capítulos de este libro resulta interesante, ya que si bien, el hilo conductor de la obra es el combate y visibilización de la violencia contra la mujer, cada autor brinda un aporte particular y único sobre esta problemática. 